\title{
Morphological and Functional Abnormalities in the Inner Retina of the $\mathrm{rd} / \mathrm{rd}$ Mouse
}

\author{
Enrica Strettoi, ${ }^{1}$ Vittorio Porciatti, ${ }^{1}$ Benedetto Falsini, ${ }^{2}$ Vincenzo Pignatelli, ${ }^{1}$ and Chiara Rossi ${ }^{1}$ \\ 1/stituto di Neurofisiologia del Consiglio Nazionale delle Ricerche, 56100 Pisa, Italy, ${ }^{2 B}$ ascom Palmer Eye Institute, Miami, \\ Florida 33101, and 3/stituto di Oftalmologia, Università Cattolica, 00168 Roma, Italy
}

\begin{abstract}
We investigated the effects of photoreceptor degeneration on the anatomy and physiology of inner retinal neurons in a mouse model of retinitis pigmentosa, the retinal degeneration (rd) mutant mouse. Although there is a general assumption that the inner retinal cells do not suffer from photoreceptor death, we confirmed major changes both accompanying and after this process. Changes include sprouting of horizontal cells, lack of development of dendrites of rod bipolar cells, and progressive atrophy of dendrites in cone bipolar cells. Electrophysiological recordings demonstrate a selective impairment of second-
\end{abstract}

Retinitis pigmentosa (RP) leads to blindness in thousands of people worldwide every year. Few if any treatments are available for this pathological condition. Among natural mutants, the retinal degeneration ( $\mathrm{rd}$ )/rd mouse displays a form of hereditary retinal degeneration that is considered a model for human RP. In this mouse, rods begin degenerating around postnatal day $(\mathrm{P}) 8$, followed by cones, and by 4 weeks virtually no photoreceptors are left (Carter-Dawson et al., 1978; Jimenez et al., 1996). Farber and Lolley (1974) and Lolley and Farber (1976) showed that degeneration is preceded by retinal accumulation of cGMP and is correlated with deficient activity of the rod photoreceptor cGMPphosphodiesterase (Bowes et al., 1990). Much of the studies devoted to the rd/rd mouse have focused on the genetics, biochemistry, and morphology of degenerating photoreceptors, with minor attention to possible effects on inner retinal cells. However, classic and recent literature proves that inner retinal neurons react to photoreceptor degeneration: a study on retinas of human RP donors (Santos et al., 1997) showed loss of inner nuclear layer (INL) and ganglion cell layer cells. Decreases in the number of ganglion cells (Stone et al., 1992), as well as alterations of the remaining rods and cones (Li et al., 1995), have been reported previously. In rat models of degeneration, histochemical changes in the inner plexiform layer (IPL) have been described (Eisenfeld et al., 1984; Lund et al., 1997), although inner retinal signaling remains sensitive (Bush et al., 1995). In rd mice, immunoreactivity for L7, a marker for on-bipolar cells, shows progressive changes (Ogilvie et al., 1997): Müller glia cells (Sheedlo et al.,

Received Dec. 27, 2001; revised March 22, 2002; accepted April 9, 2002.

This work was supported by National Institutes of Health Grant R01 EY12654 and TeleThon Project E833 to E.S. We thank Dr. S. Nakanishi for the mGluR6 antibody, Dr. M. R. Kreutz for the caldendrin antibody, and Dr. T. Curran for the disabled 1 antibody. We are grateful to Dr. Rachel Wong for her contribution in applying the technique of gene-gun staining of cells and for the gift of dye-bullets.

Correspondence should be addressed to Enrica Strettoi, Istituto di Neurofisiologia del Consiglio Nazionale delle Ricerche, Area della Ricerca, Via G. Moruzzi 1, 56100 Ghezzano, 56100 Pisa, Italy. E-mail: strettoi@in.pi.cnr.it.

Copyright (ㄷ) 2002 Society for Neuroscience $0270-6474 / 02 / 225492-13 \$ 15.00 / 0$ order neurons that is not predictable on the basis of a pure photoreceptor dysfunction. Our data point out the necessity to prove integrity of the inner retina before attempting restoring visual function through photoreceptor intervention. This is even more important when considering that although intervention can be performed before the onset of any symptoms in animals carrying inherited retinopathies, this is obviously not true for human subjects.

Key words: bipolar cells; dendritic remodeling; sprouting; retinitis pigmentosa; ERG; morphology

1995; Chaitin et al., 1996) and rod bipolar cells (Kwan et al., 1999) are altered, as well as GABA and GABA-receptor immunoreactivity in the INL (Yazulla et al., 1997). Studies on mice with a different photoreceptor alteration ("retinal degeneration slow" or rds mice) have shown that at late stages of photoreceptor loss, the INL becomes thinner and irregular (Sanyal et al., 1980), whereas the morphology of surviving rods becomes altered (Jansen and Sanyal, 1992). In certain forms of RP, there are morphological and electrophysiological abnormalities in postreceptoral cells (Fariss et al., 2000). Retinal electrophysiological studies of RP patients (Cidecyian and Jacobson, 1993; Falsini et al., 1994) indicate dysfunctions at or beyond the receptor synapse.

Recently it has been shown that mutated photoreceptors can be rescued by various approaches, including somatic and vectorbased gene therapy (Bennett et al., 1996, 1998; Jomary et al., 1997; Ali et al., 2000; Acland et al., 2001; Takahasi et al., 1999), administration of survival factors (Frasson et al., 1999; Ogilvie et al., 2000), and transplantation of intact retinal sheets (Gouras et al., 1994; Woch et al., 2001). The increasing efficacy of these strategies demands an assessment of the long-term preservation of the inner retinal structure despite the loss of photoreceptors: partial rescue of photoreceptors would be doomed to failure if inner retinal layers had been irreversibly affected by even partial photoreceptor loss.

The central purpose of our study was to test the integrity of the inner retina in the $\mathrm{rd} / \mathrm{rd}$ mutant mouse. We used anatomical and electrophysiological techniques to reveal modifications in the inner retina after photoreceptor loss. We have shown previously that in the $\mathrm{rd} / \mathrm{rd}$ mutant, rod bipolar and horizontal cells undergo profound morphological alterations (Strettoi and Pignatelli, 2000). Here, we describe additional alterations in cone bipolar cells at later stages of photoreceptor degeneration, as well as functional abnormalities that are detectable very early in the animal's life. At least some types of amacrine cells, on the contrary, appear normal. Overall, we provide a systematic analysis of the $\mathrm{rd} / \mathrm{rd}$ retina structure and function that casts doubt on 


\begin{tabular}{|c|c|c|c|}
\hline Antigen & Antiserum & Localization & rd Anomalies \\
\hline $\mathrm{PKC} \alpha$ & $\begin{array}{l}\text { Mouse anti-PKC } \alpha \\
\text { Rabbit anti-PKC } \alpha\end{array}$ & Rod bipolar cells & Absence of dendritic arborization \\
\hline L7 & Mouse anti-L7 & Rod bipolar cells & Absence of dendritic arborization \\
\hline $\mathrm{G}_{\mathrm{O}} \alpha$ & Mouse anti- $\mathrm{G}_{\mathrm{O}} \alpha$ & $\begin{array}{l}\text { Rod bipolar cells } \\
\text { On-cone bipolar cells }\end{array}$ & $\begin{array}{l}\text { Absence of dendrites } \\
\text { Late loss of dendritic arborizations }\end{array}$ \\
\hline Caldendrin & Rabbit anti-caldendrin & Cone bipolar cells & Late loss of dendritic arborizations \\
\hline Neurokinin 3 receptor (NK3) & Rabbit anti-NK3 & Cone bipolar cells & Late loss of dendritic arborizations \\
\hline Calbindin & $\begin{array}{l}\text { Mouse anti-calbindin D } \\
\text { Rabbit anti-calbindin D }\end{array}$ & Horizontal cells & $\begin{array}{l}\text { Loss of organization, hypertrophy of } \\
\text { cell bodies }\end{array}$ \\
\hline Neurofilament $200 \mathrm{kDa}$ & $\begin{array}{l}\text { Mouse anti-neurofilament } \\
200 \mathrm{kDa} \\
\text { Rabbit anti-neurofilament } \\
200 \mathrm{kDa}\end{array}$ & $\begin{array}{l}\text { Horizontal cells axonal } \\
\text { arborizations }\end{array}$ & $\begin{array}{l}\text { Anomalous development, loss of thin } \\
\text { fibers, widening of the arbors }\end{array}$ \\
\hline mGluR6 & Rabbit anti-mGluR6 & On-bipolar cells dendritic tips & Altered localization, decreased staining \\
\hline Glutamine synthetase (GS) & Mouse anti-GS & Müller cells & \\
\hline Glial fibrillary acidic protein (GFAP) & Rabbit anti-GFAP & Müller cells & Increased reactivity \\
\hline Disabled 1 & Rabbit anti-disabled 3 & All amacrine cells & \\
\hline Choline acetyl transferase $(\mathrm{CHaT})$ & Goat anti-CHAT & Cholinergic amacrine cells & \\
\hline Tyrosine hydroxylase $(\mathrm{TH})$ & Rabbit anti-TH & Dopaminergic amacrine cells & \\
\hline
\end{tabular}

the long-held dogma according to which inner retinal neurons are relatively insensitive to photoreceptor degeneration.

\section{MATERIALS AND METHODS}

All experimental procedures were done in compliance with the Association for Research in Vision and Ophthalmology Statement for the Use of Animals in Ophthalmology and Vision Research and with the rules for animal experimentation of the Italian Ministry of Health.

\section{Animals}

$\mathrm{rd} / \mathrm{rd}$ mutant mice of the C3HPde strain and wild-type (wt) mice of the C57BL/6J strain were used for the present study. Animals were kept in an artificial $12 \mathrm{hr}$ light/dark cycle, with the illumination level below 60 photopic lux.

\section{Histology}

Immunocytochemistry. Adult (1-3 months) mice were anesthetized with an intraperitoneal injection of avertin $(15 \mathrm{mg} / \mathrm{kg})$ and perfused transcardially with $4 \%$ paraformaldehyde (PAF) in $0.1 \mathrm{~m}$ phosphate buffer. Young animals $(10-20 \mathrm{~d})$ were enucleated under anesthesia, and their eyes were immersion fixed in PAF. For immunocytochemistry (ICCH) on sections, whole eyes were sucrose infiltrated, frozen, and serially sectioned at $14 \mu \mathrm{m}$ on a cryostat. Sections from groups of three agematched animals of the same strain were mounted on the same slide to ensure minimal differences in tissue handling and allow ready comparisons. ICCH was also performed on retinal whole mounts after retinal isolation from the eyecup following fixation. ICCH protocols were described in Strettoi and Pignatelli (2000). Primary antibodies were as follows: mouse and rabbit anti-protein kinase $\mathrm{C} \alpha$ (PKC; Sigma); rabbit anti-L7 (from Dr. C. Cepko, Harvard Medical School, Boston, MA); rabbit anti-mGluR6 (from Dr. S. Nakanishi, Osaka University, Osaka, Japan); mouse and rabbit anti-calbindin D-28k [Swant; Haverkamp and Wassle (2000)]; mouse and rabbit anti-caldendrin (from Dr. M. R. Kreutz, Leibniz Institute for Neurobiology, Magdeburg, Germany); rabbit anti-neurokinin 3 (NK3, Nova Biological); mouse anti- $\mathrm{G}_{\mathrm{o}} \alpha$ (Chemicon); mouse and rabbit anti-neurofilament $200 \mathrm{kDa}$ (clone N52; Sigma); mouse anti-glutamine synthetase (Chemicon); rabbit anti-glial fibrillary acidic protein (GFAP, Sigma); goat anti-choline acetyl transferase (ChAT; Chemicon); rabbit anti-tyrosine hydroxylase (TH; Chemicon); and rabbit anti-disabled 1 (from Dr. T. Curran, St. Jude Children's Research Hospital, Memphis, TN). A synopsis of all the antibodies used is shown in Table 1 . Secondary antibodies were anti-mouse-Oregon Green 488 and anti-rabbit-Alexa 568 (Molecular Probes; used for single and double staining) or anti-rabbit and anti-goat conjugated with Cy3
(Sigma; used for single staining). Retinal preparations were examined with a Leica TCS-NT confocal microscope equipped with a kryptonargon laser. To compare retinal cell morphologies in wild-type and rd preparations, the following parameters were matched: age; fixation and immunostaining protocols; retinal eccentricity, measured as a distance from the optic nerve head; magnification, pinhole size, gain and offset of the confocal microscope; and thickness of extended-focus images obtained at the confocal. Files were saved in TIFF format and exported on an image analyzer (MCI4, Imaging) for morphometry. Three to four littermates for each strain for each age (P10, P20, P30, P90) were used for $\mathrm{ICCH}$ on vertical sections and reacted with the full panel of antibodies listed above; whole-mount ICCH was performed on P10 and P20 retinas to reveal calbindin D and neurofilaments (three retinas, for each age, for each strain of mice). Eighteen retinas ( $9 \mathrm{wt}$ and $9 \mathrm{rd}$ ) were used for whole-mount ICCH for the following antibodies: $\mathrm{PKC} / \mathrm{G}_{\mathrm{o}} \alpha, \mathrm{TH}$, and ChAT. Counts of TH-positive cells were performed on photographic montages of the whole extensions of four retinas for each strain of mice at P90. Counts of ChAT-positive amacrine cells were performed on three retinas for each strain of mice at P90, following the methods described in Galli-Resta et al. (2000). A total of 50 animals were used for ICCH. Quantitative analysis of sprouts emerging from cell bodies and dendrites of horizontal cells at P10 was performed as follows: sections from six retinas, three from rd and three from wild-type mice, aged P15, were reacted in parallel and stained with calbindin D antibodies. Images of identical size from three adjacent sections from each retina at similar eccentricities were obtained at the confocal microscope and exported on the image analyzer. Sprouts encountered within a linear extension of 2.5 $\mathrm{mm}$ were counted systematically. Counts from rd and wt were compared.

Electron microscopy. Two additional mice (1 rd and $1 \mathrm{wt}), 3$ months old, were anesthetized and perfusion fixed for electron microscopy with a mixture of $2.5 \%$ glutaraldehyde and $2 \%$ paraformaldehyde in buffer. After enucleations, retinas were isolated, dissected into small blocks, postfixed with osmium tetroxide, bloc stained with uranyl acetate, dehydrated in ethanol, and embedded in Epon/Araldite. Ultrathin sections were obtained from central retinal areas, collected on grids, and examined with a Jeol 1200EX II electron microscope. Photographs were obtained of rod bipolar axonal endings in sublamina 5 of the inner plexiform layer. Negatives were printed at a final magnification of $25,000 \times$. Rod bipolar axonal endings were identified by their typical morphology, analyzed with respect to synaptic contacts, and measured along their major axis. A total of 20 endings from wt and an equal number from rd retinas were examined.

Gene-gun labeling. Single-cell staining with DiI and DiO was performed with a helium gene gun (Bio-Rad) according to the protocol 
described in Gan et al. (2000). Briefly, the gene gun was loaded with single DiI and DiO bullets and set up at a pressure of 60-80 psi. Retinas were dissected from quickly enucleated eyes of three wt and three rd animals that were 3 months old. Retinas were kept in ice-cold, oxygenated saline solution for $5 \mathrm{~min}$ and then were placed receptor-side up on Millipore filter paper, dried, and exposed to a single shooting of dye. After successful stain, retinas were fixed for $30 \mathrm{~min}$ in $2 \%$ PAF, rinsed in buffer, and examined at the confocal microscope. To expose inner retinal neurons from wt retinas before shooting them with the gene gun, the outer layers were removed by gentle stripping with Millipore filter paper that was placed on the outer retinal surface. A total number of 9 rd and $3 \mathrm{wt}$ axonal arborizations of horizontal cells were examined.

\section{Electrophysiology}

Twenty-six rd/rd mice, ages $12-14$ d to 3.5 months, and 24 wt mice as controls in the same age range were tested. Additional recordings were performed on mice expressing the rd mutation on the C57 background, obtained by back-crossing for more than eight generations. No differences were detected between these rd mutants and those from the $\mathrm{C} 3 \mathrm{H}$ strain.

Animals were dark adapted overnight and anesthetized under dim light; their pupils were dilated with $1 \%$ atropine (Tubilux Pharmaceuticals). ERGs were recorded by corneal $\mathrm{Ag}-\mathrm{AgCl}$ rings inserted below the eyelids in response to $50 \mu \mathrm{sec}$ broad-band white flashes of varying intensity delivered by a standard Ganzfeld stimulator (Lace Elettronica, Pisa, Italy). Background light for light-adapted recordings was by the same Ganzfeld system. The intensity of stimulation and background was controlled with neutral density filters. Flash intensity varied between 0.2 and 20 photopic $\mathrm{cd} / \mathrm{m}^{2}$ per second. Background intensity was set at 12 $\mathrm{cd} / \mathrm{m}^{2}$, except for one experiment in which it was changed to between 12 and $600 \mathrm{~cd} / \mathrm{m}^{2}$. At the position occupied by the mouse eye during experiments, directional variations of light intensity did not exceed $\pm 15 \%$ of the average intensity.

Electrical signals were differentially amplified 5000-fold with a high common mode rejection amplifier (Lace Elettronica), bandpass filtered between 0.1 and $1000 \mathrm{~Hz}$, and digitized on-line at $2 \mathrm{kHz}$ with 12 bit accuracy. Digital signals were signal averaged (up to 50 waveforms, depending on the noise level) and stored on a PC disk. Partial blocks (two to six packets) of the total average were also stored to verify reproducibility of waveforms. The interval between repeat flashes was set to allow complete recovery of the b-wave between flashes, except for one series of experiments in which responses were collected at different stimulus repetition rates (flicker) between 0.1 and $20 \mathrm{~Hz}$.

Electroretinographic a- and b-waves were quantified in their amplitude (baseline to negative a-wave peak, a-wave to positive b-wave peak) and time-to-peak (from stimulus onset to negative a-wave or positive b-wave peak). For b-wave analysis, oscillatory potentials (Peachey et al., 1993; Lyubarsky et al., 1999) were removed by digital filtering. The lightintensity dependence of the a- and b-wave amplitudes, measured at fixed times after stimulus onset, was determined (Robson and Frishman, 1995, 1996; Rohrer et al., 1999). Normalized initial slopes (Rohrer et al., 1999) of both ERG components were also estimated and plotted as a function of light intensity. The initial slope was measured as the slope of the tangent that best fits the initial decline (for the a-wave) or rise (for the b-wave) of the normalized waveform. The results were averaged, and comparisons were made among averaged values. Errors are presented as SDs. To determine statistical significance, Student's two-tailed $t$ test or ANOVA was used; $p<0.05$ was considered statistically significant.

\section{RESULTS}

\section{Anatomy}

We compared systematically rod and cone bipolar cells, horizontal cells, Müller glial cells, and some types of amacrine cells of rd and wt retinas from $\mathrm{P} 10$ to $\mathrm{P} 90$.

On P10, many rows of photoreceptors are still present in the rd retina, although their death process is actively taking place. Synaptogenesis is effective in both plexiform layers. Most of the cell types examined at this age appear indistinguishable from their wt counterparts; namely, the dendrites of rod bipolar cells are very similar in wt and rd, on P10, and axonal arborizations of rod bipolar cells, in both strains, appear to be constituted of large clusters of small varicosities, extending into sublaminas 4 and 5 of the IPL. We have shown previously (Strettoi and Pignatelli, 2000) that the metabotropic glutamate receptor, mGluR6, normally placed at the dendritic tips of rod bipolars and depolarizing cone bipolars (Vardi et al., 2000), has a distribution typical of the immature cells: staining is present in cell bodies, in dendrites, and occasionally in axons of bipolar cells. Horizontal cell bodies and axonal complexes appear normal.

$\mathrm{G}_{\mathrm{o}} \alpha$ (labeling depolarizing bipolar cells) (Vardi, 1998) and caldendrin (revealing subtypes of cone bipolar cells) (Haverkamp and Wassle, 2000) display a normal distribution. Glutamine synthetase, a cell-specific enzyme of Müller cells, reveals the full profiles of Müller cells, whereas immunoreactivity for GFAP is absent from them.

On P15, a difference in the thickness of the photoreceptor layer is evident between wt and rd retinas. Death of photoreceptors in the rd has reduced the outer nuclear layer (ONL) to approximately six rows of photoreceptor nuclei. Some modifications start to become evident among second-order neurons. In particular, neurofilament and calbindin immunocytochemistry reveal sprouting of processes from horizontal cells, which are mostly originating from processes emerging from axonal complexes (Fig. 1). Sprouts are represented by long thin neurites directed toward the IPL. Quantitative analysis of sections stained with calbindin D antibodies reveal that sprouts in the rd retina are 10 times more numerous than in the retina of the wt, in which they are found occasionally (Fig. 2).

Müller cells display signs of hyper-reactivity because they label for GFAP. Upregulation of GFAP has been described previously in other forms of retinal degeneration as a sign of glial reaction (Sheedlo et al., 1995; de Raad et al., 1996; Wang et al., 2000; Zeng et al., 2000).

At this age, other cell types (rod and cone bipolar cells and dopaminergic, cholinergic, and AII amacrines, which represent the major output neurons of rod bipolar cells) appear normal.

\section{$P 18-P 20$}

Only scattered photoreceptor nuclei are left in the ONL of the rd mouse retina. At this age, synaptogenesis is completed (Blanks et al., 1974a,b; Horsburgh and Sefton, 1987). Major changes are evident in the retina of the rd: dendrites of rod bipolar cells have disappeared from the central retina, and in the periphery, their growth has been arrested. As a consequence, mGluR6 has become spatially disorganized. Immunoreactivity appears clustered in the OPL, whereas persistent labeling of axons is mostly evident in the INL (data not shown). Rod bipolar axonal endings are unchanged as compared with P10 in the rd. In the wt, on the contrary, they have grown noticeably to reach the adult size (Fig. 3). Horizontal cell bodies are still normal, whereas axonal arborizations have undergone further modifications. This is mostly visible in whole-mount retinal preparations reacted with antibodies against neurofilaments (Fig. 1). Although processes of axonal complexes form a regular spider web with tight meshes in the wt, the same processes appear hypertrophic in the rd, and at the same time they cover poorly the retinal surface as a loose net. Finally, although the general morphology of Müller cells is normal as revealed by glutamine synthetase $\mathrm{ICCH}$, there is still increased reactivity for GFAP. $\mathrm{G}_{\mathrm{o}} \alpha$ and caldendrin are still very similar to normal. 


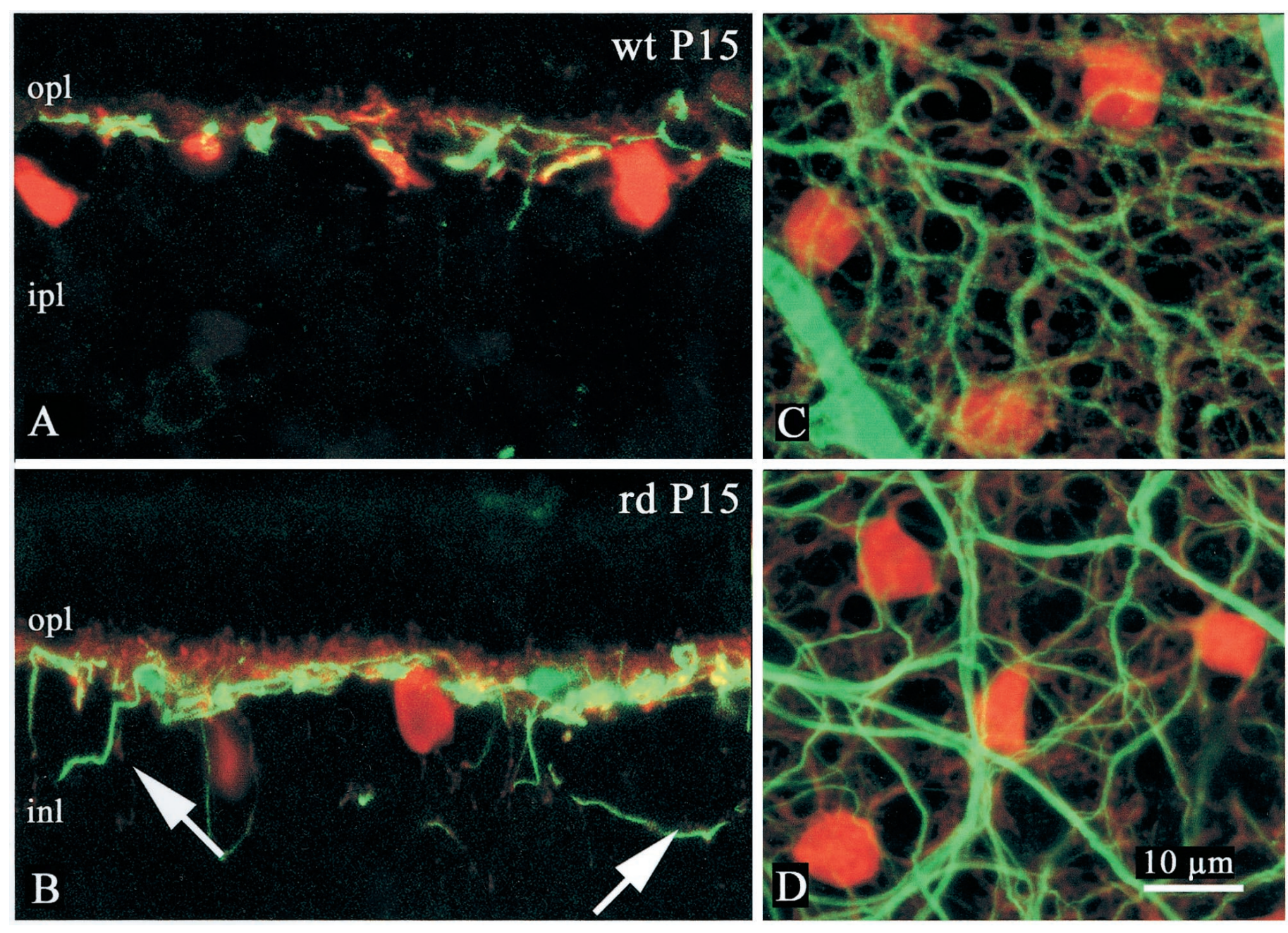

Figure 1. Early modifications in horizontal cells. A, B, Vertical sections of P15 retinas, wt and rd. Red labeling indicates calbindin. Green labeling indicates neurofilament antibodies. A rich complement of neurites emerges from the axonal complexes of horizontal cells in the retina of the mutant mouse (arrows in $B$ ) and ramifies in the inner nuclear layer (inl). $C$ (normal retina) and $D$ (rd retina) show whole-mount preparations from animals at P19. Staining is the same as above. At this developmental stage, it is already evident that the axonal arborizations of horizontal cells, stained in green, are hypertrophic in the rd and form a loose meshwork of processes in the outer plexiform layer of the retina.

\section{P30}

Almost no rod photoreceptors are left by this stage in the rd retina (Jimenez et al., 1996; LaVail et al., 1997). Leftover dendrites of rod bipolars, particularly from the peripheral retina, have undergone progressive retraction. There is also a visible difference in size between single axonal endings of rod bipolars in rd and wt. This is confirmed by electron microscopy performed at later stages. Individual rod bipolar endings, measured in sublamina 5 of the IPL, are noticeably smaller in the rd as compared with the wt ( 2.2 vs $3.5 \mu \mathrm{m} ; n=20 ; \mathrm{SE}=1 \mu \mathrm{m})$. In addition, synaptic ribbons are smaller and ball shaped (Fig. $3 D, H$ ). These ultrastructural features are typical of immature bipolar endings. Overall, rod bipolars in the rd retina appear frozen in a late developmental stage.

As reported in a previous paper (Strettoi and Pignatelli, 2000), there is a decreased immunoreactivity (IR) for mGluR6, which is condensed in irregular clusters in the OPL, most probably corresponding to dendrites of depolarizing cone bipolars. There is persistent immunoreactivity in axons of bipolar cells in the rd.

ICCH for $\mathrm{G}_{\mathrm{o}} \alpha$ labels both rod and depolarizing cone bipolars (Vardi, 1998). Thus, double staining with this antibody and PKC

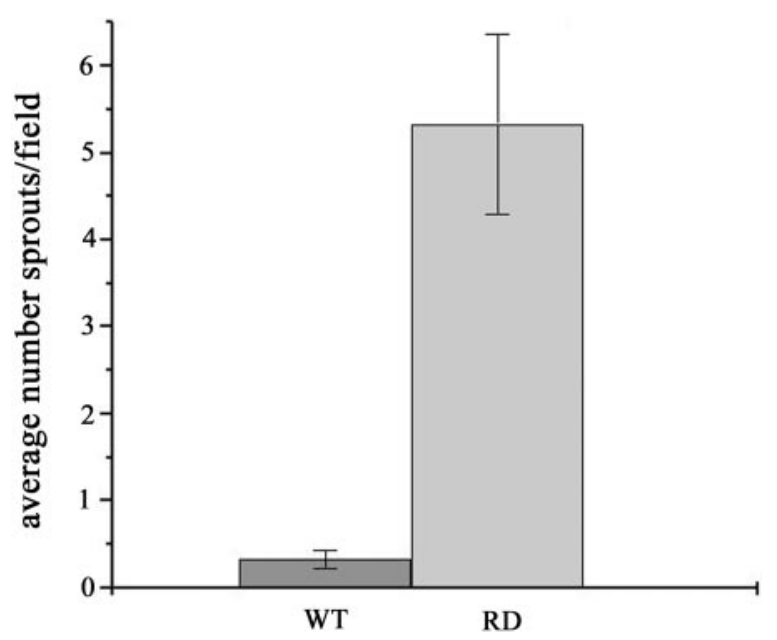

Figure 2. Horizontal cell sprouting at P15. Counts refer to sprouts encountered within a linear extension of $120 \mu \mathrm{m}$. Data are shown as averages with SEs. The high number of ectopic processes in the mutant is evident as compared with the normal retina. 

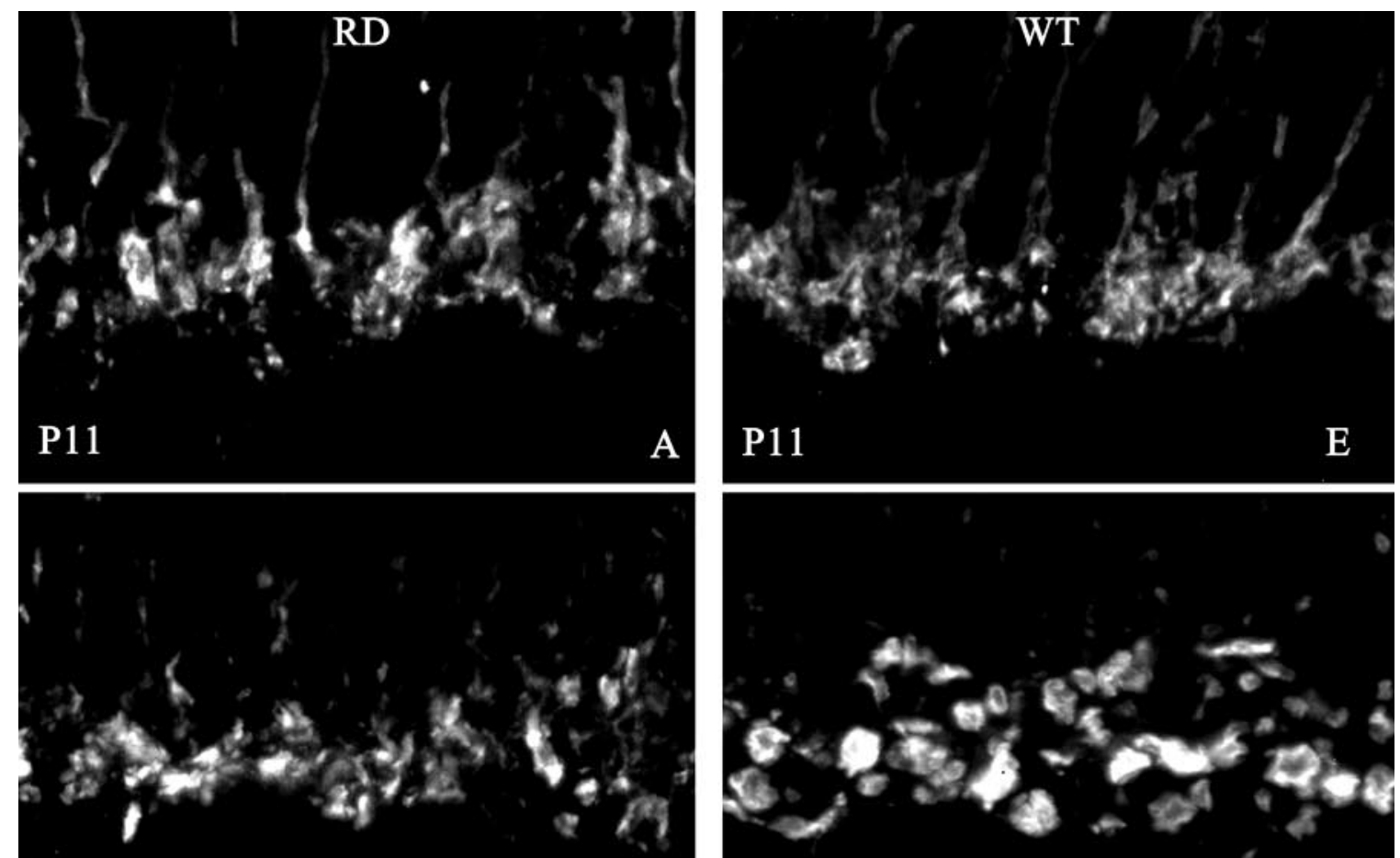

P19

B
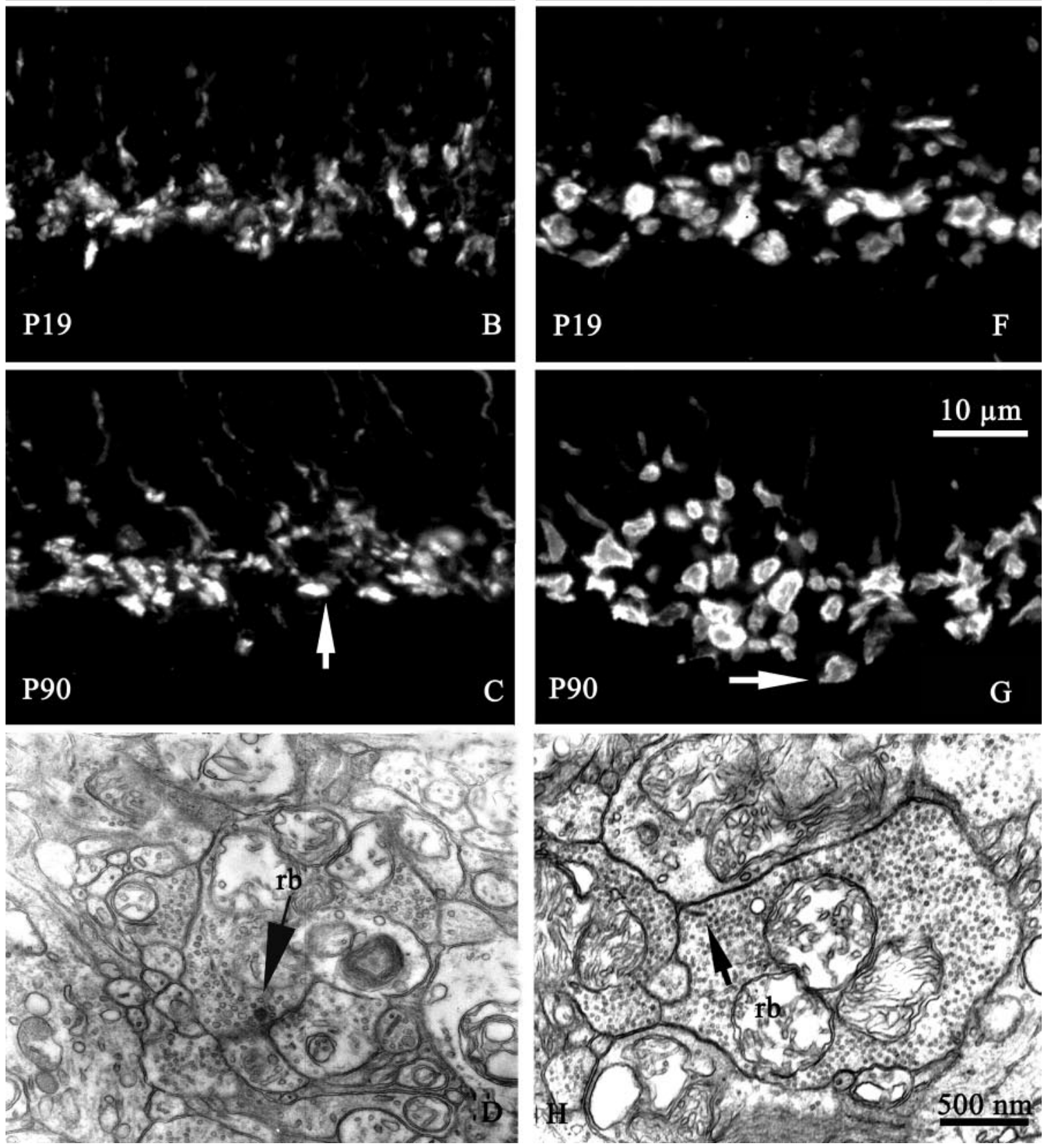

Figure 3. Rod bipolar endings in the rd (left) and wt (right) retinas, at various developmental stages. PKC staining reveals an arrested development in the morphology of axonal arborizations of rod bipolar cells. At P11, endings are indistinguishable in the two strains. At P19, the growth that has taken place in the wt is already evident compared with the nonvaried size in the rd. In the adult animal, large varicose endings in the wt are paralleled by atrophic varicosities in the rd (arrows in $C, G)$. Electron microscopy $(D, H)$ reveals that single axonal endings are smaller in the rd and also carry synaptic ribbons $(r b)$ of anomalous round shape, recalling the morphology found at immature synapses. 

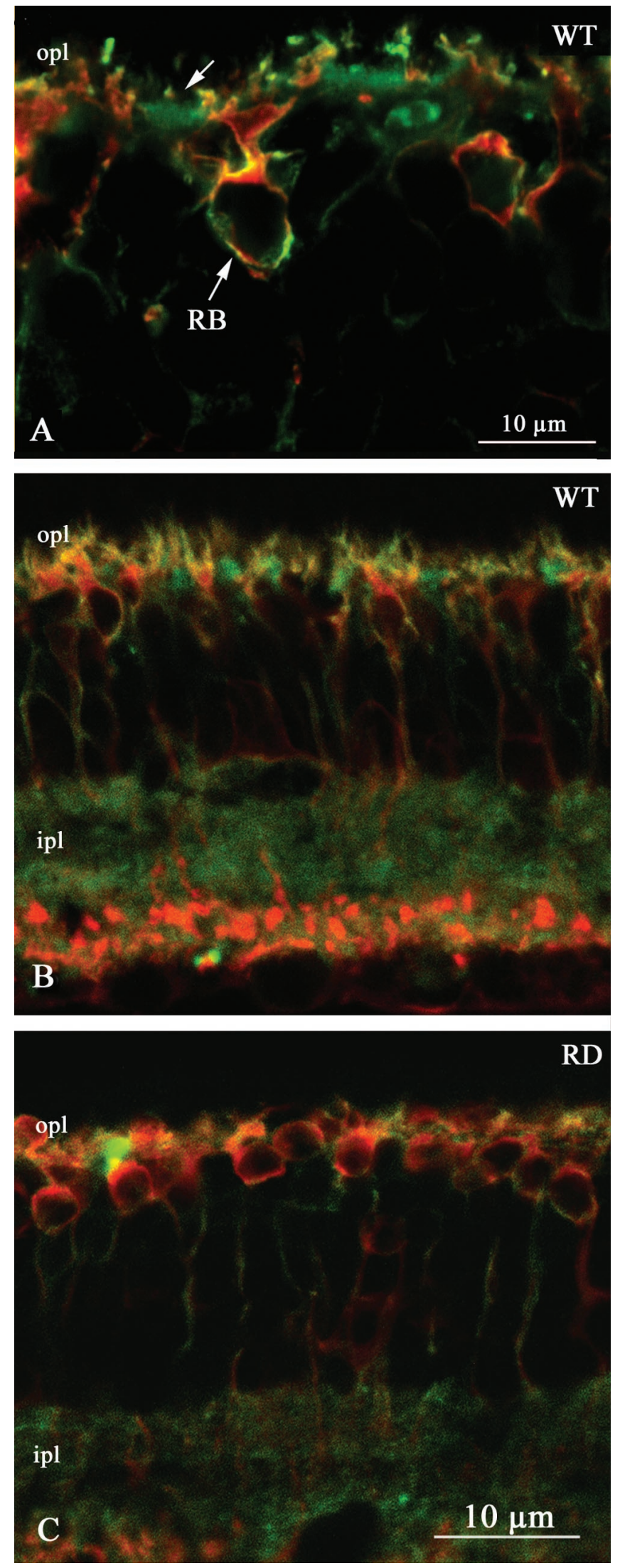

Figure 4. Dendritic changes in depolarizing cone bipolars and rod bipolars, revealed by $\mathrm{G}_{\mathrm{o}} \alpha$ (green) and PKC (red) antibodies. In the retina of the wt $(A)$, green staining in the OPL has the form of dots, corresponding to the apical dendrites of bipolar cells entering the synaptic pedicles of is necessary to distinguish between cellular types. In the wt, regularly spaced spherical formations appear in the OPL. They exhibit $\mathrm{G}_{\mathrm{o}} \alpha$-IR but lack PKC-IR (Fig. $4 A, B$ ), and they correspond to apical dendrites of depolarizing cone bipolars, entering the synaptic pedicles of cone photoreceptor to establish contacts in the OPL. Cone bipolar staining reveals differences, because in the rd it appears less regularly organized in space, with clustered dendrites in the OPL. The fine geometry of apical dendrites has been totally lost in the rd by P30 (Fig. 4C).

Horizontal cell bodies are still regularly arranged in space, but axonal complexes are very poorly organized, with uneven, large holes formed by their loose processes in the OPL. At the singlecell level, as shown by gene-gun staining with carbocyanine dyes (Fig. 5), this corresponds both to hypertrophy of individual, large-size processes and to complete loss of fine-size dendrites, which are normally postsynaptic to rods.

Caldendrin immunostaining (Fig. $6 A, B$ ) and NK3 labeling (Fig. $6 C, D$ ) also reveal a progressive retraction of cone bipolar dendrites in the OPL, because the normal thin layer, well evident in the retina of the wt, has been drastically reduced in the retina of the rd. GFAP hyper-reactivity, on the contrary, has been reduced in Müller cells.

\section{P90}

At this late stage of photoreceptor degeneration, all of the second-order neurons that we have examined show major alterations (Figs. 3, 4, 6). Rod bipolars have totally lost even the few dendrites that had developed successf ully. Cone bipolars (belonging both to the "on" and to the "off" physiological varieties) also lost their dendritic complements, as shown by caldendrin, NK3, and $\mathrm{G}_{\mathrm{o}} \alpha$ immunostaining. Horizontal cells bodies, as well as axonal arborizations, are hypertrophic, whereas thin processes, emerging either from bodies or axonal endings, have been lost. We have shown previously that by this stage there is a loss of both rod bipolars and horizontal cells from the central retina, both reaching 30\% (Strettoi and Pignatelli, 2000).

At all the ages examined, we found no changes in the morphology and organization of three of the best-characterized types of amacrine cells: starburst cholinergic amacrines, dopaminergic amacrines, and AII amacrines. Starburst amacrines are large-field cells that occur in two mirror-symmetric populations, the cell bodies of which are located in the inner nuclear layer and the ganglion cell layer, with dendrites forming two bands in the outer and inner third of the IPL, respectively (Famiglietti, 1983). Their number has been estimated for the retina of various mammals, including the mouse (Jeon et al., 1998). Their general morphology and pattern of stratification do not vary in the retina of rd mice up to 3 months of age (data not shown). Their number also remains unchanged $(16,174 \pm 415$ cells in the rd vs $16,869 \pm 400$ cells found in the wt).

Dopaminergic amacrines are interplexiform cells: they have wide dendritic arbors that ramify extensively in the outermost lamina of the IPL. From these dendrites, a plexus of radially oriented processes originates and runs toward the outer retina, to end freely in the OPL. Dopaminergic amacrine cells are present in the retina in very low number; there are 450 cells in the retina

individual cones (arrow). Dendrites form a continuous layer. Dendrites of rod bipolars $(R B)$, labeled by both antibodies, appear orange-yellow $(B)$. In the $\mathrm{rd}(C)$, both the green layer and the yellow dendrites have disappeared from the outer plexiform layer $(o p l)$. Animals are 3 months old. 

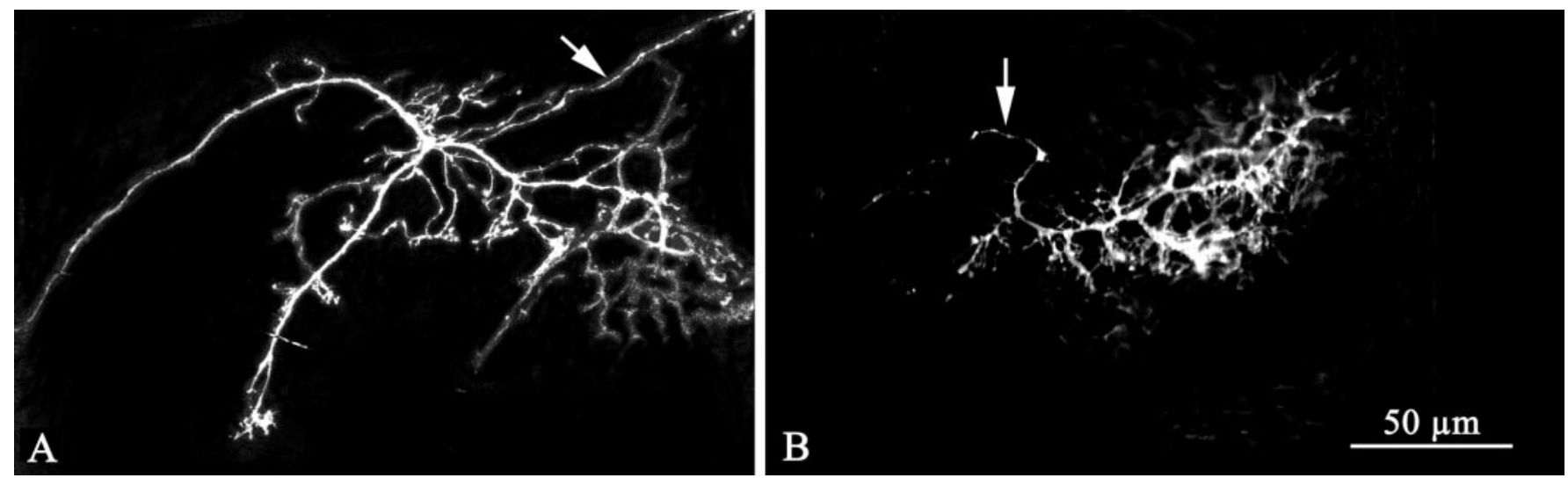

Figure 5. Late-stage modifications of horizontal cell axonal arbors. Shown are single axonal arborizations of adult rd (left) and wt (right) retinas, stained by gene-gun delivery of DiI. The enlargement of both the whole arborization in the rd and the hypertrophy of single, large-size processes are evident. Thin ramifications have been lost. Arrows point to axons.
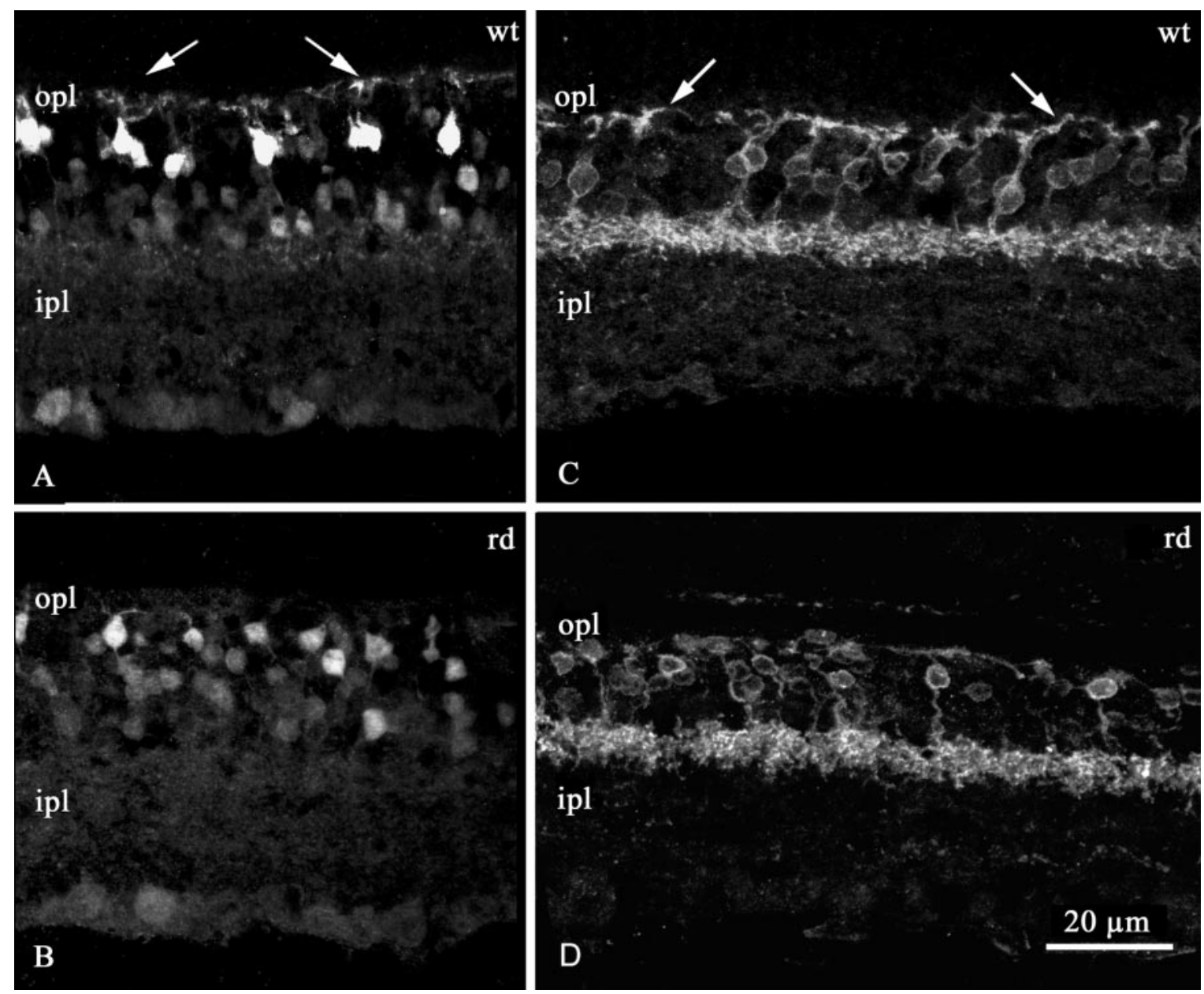

Figure 6. Dendritic loss in selective cone bipolars types. Caldendrin staining reveals a variety of both on and off cone bipolars, the dendrites of which form a continuous, thin layer in the outer plexiform layer (opl) of the wt $(A$, arrows). In the adult rd $(B)$, at later stages of photoreceptor degeneration, this layer has totally disappeared, whereas the intensity of cell body staining has remained unchanged. A similar decrement of dendritic arbors is revealed by NK3 staining, shown in $C$ for the retina of the wt and in $D$ for that of the rd, that labels one variety of cone bipolar cells, the axons of which ramify in the outer portion of the IPL (ipl).

of the mouse (Gustincich et al., 1997). We found a comparable number in the retina of the rd (452 cells per retina; $\mathrm{SE} \pm 30$; four retinas sampled,). Their morphology was also normal in the retinas of rd mutant mice (data not shown).
Finally, AII amacrines represent the largest population of amacrine cells in the mammalian retina. They can be labeled by means of disabled 3 antibodies (Rice and Curran, 2000). Because they receive a major synaptic input from rod bipolar cells (Strettoi 

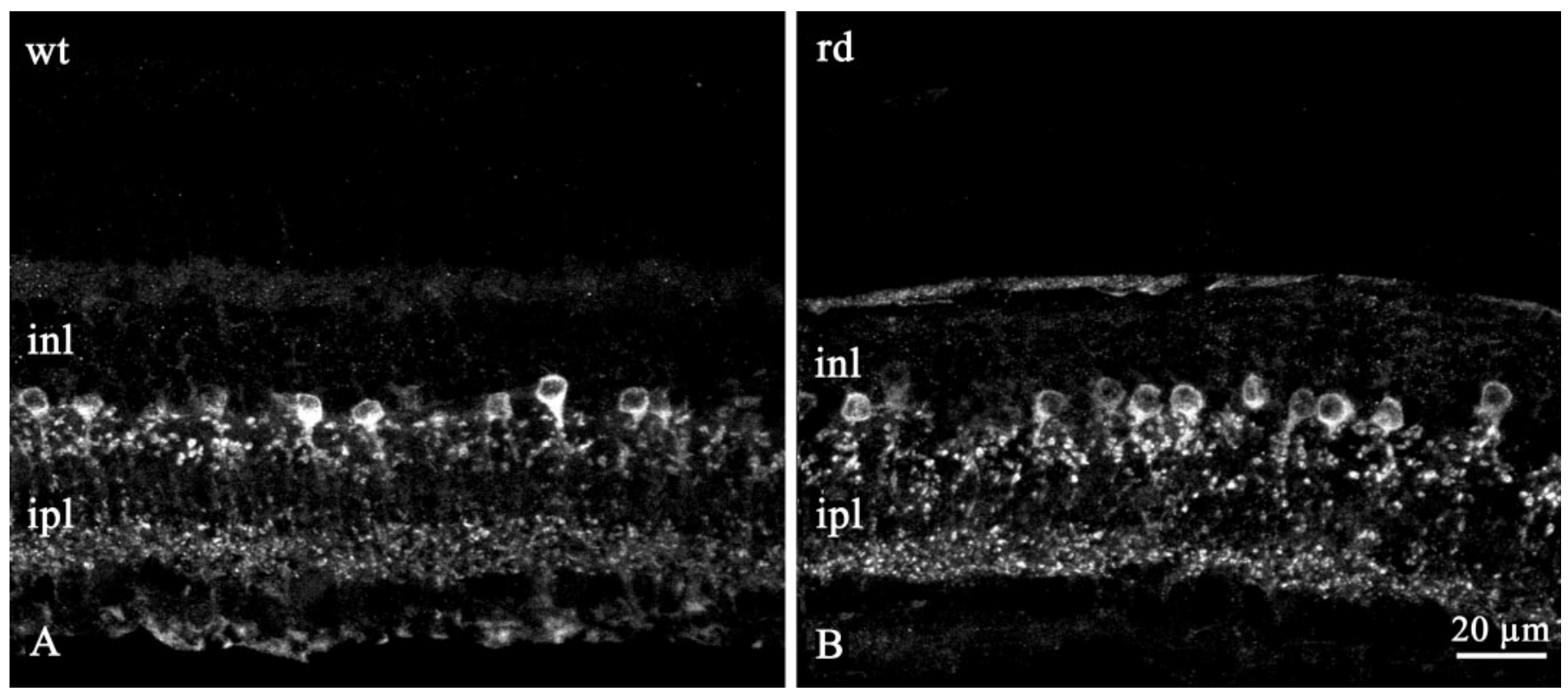

Figure 7. Vertical sections from wt $(A)$ and $\mathrm{rd}(B)$ retinas, reacted with antibodies to the protein disabled 1. AII amacrine cells are labeled. These are characteristic cells, which display bi-stratified dendrites that span both the outer and inner halves of the IPL (ipl). Their morphology is normal in the rd.

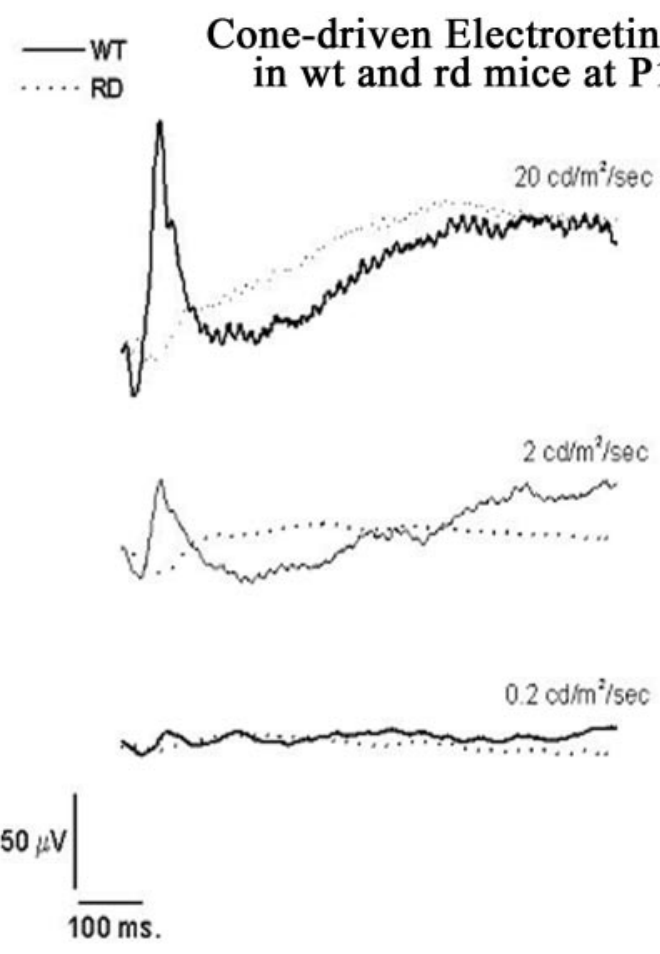

\section{Electroretinogram parameters in wt and rd mice at P14}

$0.2 \mathrm{od} / \mathrm{m}^{2} / \mathrm{sec}$

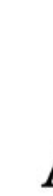

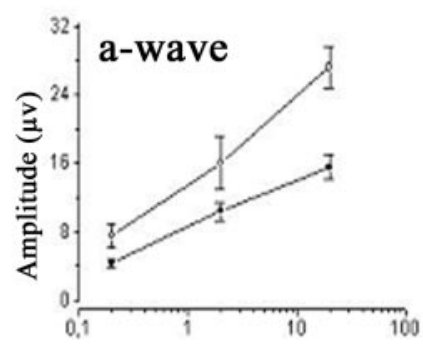
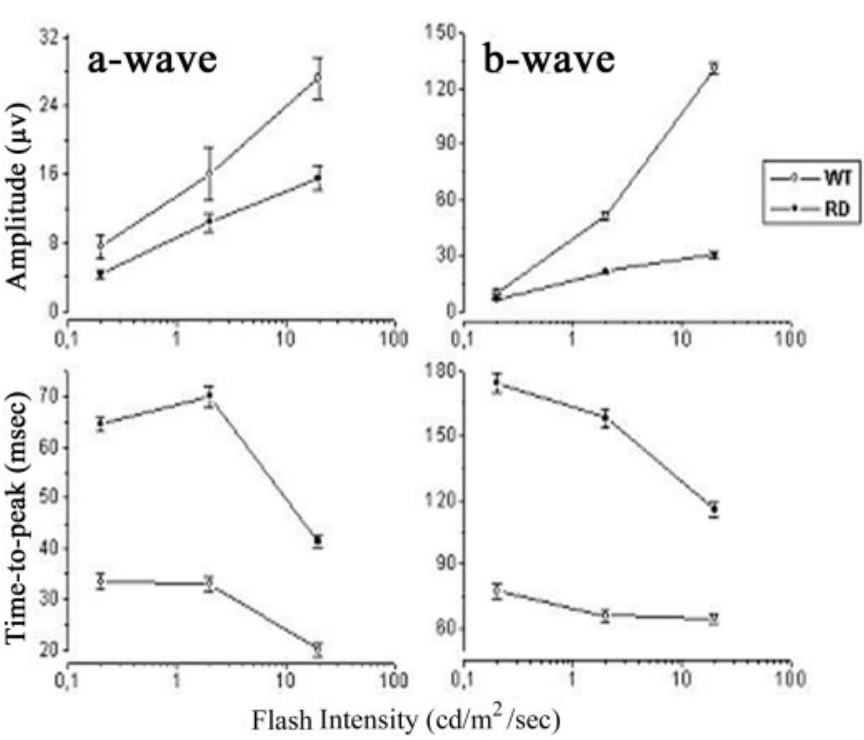

A

B

Figure 8. A, Cone-mediated ERGs recorded at different stimulus intensities in a wt and an rd mouse at P14-15. Note the sluggish rd b-wave response and its prolonged latency and duration as compared with the control animal. B, Amplitudes and times-to-peak of cone ERG a- and b-wave components plotted as a function of stimulus intensity for the wt and rd mice.

et al., 1992), we expected to find some abnormalities in this type of amacrine as a secondary effect of morphological variations of rod bipolar cells. However, their general morphological features appeared well preserved at all the ages tested (Fig. 7). We cannot exclude the possibility, however, that changes in their number or dendritic organization occur later in time.

\section{Electrophysiology}

No electroretinographic responses at flash intensities below cone threshold could be elicited at any age in the rd mice. Therefore, an appropriate comparison between wt and rd mouse ERGs was attainable only for cone-mediated responses. It has been shown previously that for adult mice, cone-mediated ERGs can be 

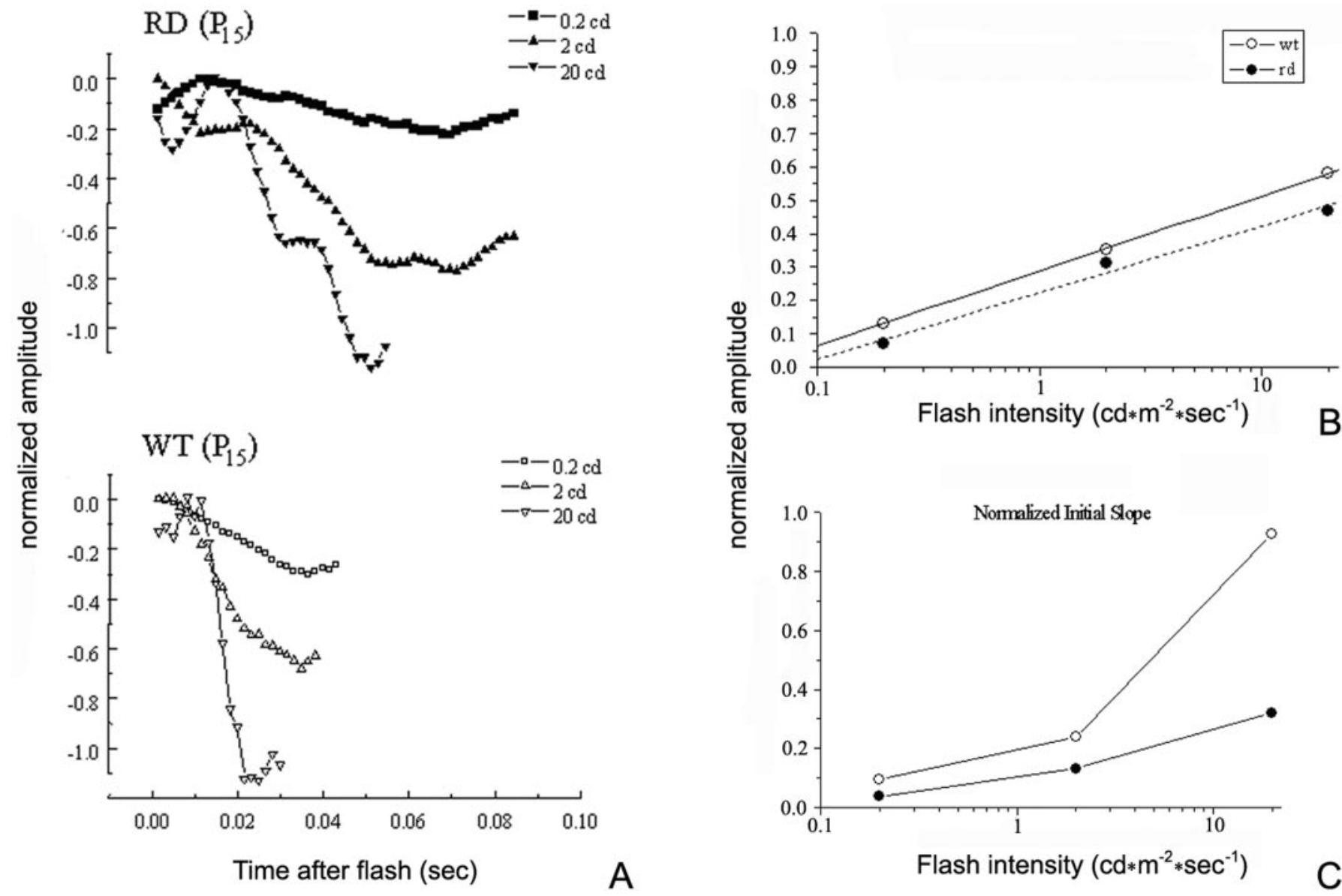

Figure 9. $A$, A-wave response families recorded at increasing intensities $\left(0.2,2\right.$, and 20 photopic $\mathrm{cd} / \mathrm{m}^{2}$ per second) from an $\mathrm{rd}$ and a wt mouse. $B$, Normalized amplitudes, measured at fixed times after stimulus onset, and the normalized initial slopes (see Materials and Methods) of the rd and control a-waves shown $A$.

isolated by suppressing rod circulating current by means of a steady light-adapting background (Peachey et al., 1993). It has also been demonstrated (Pugh et al., 1998; Lyubarsky et al., 1999) that a background intensity producing 4000-6000 photoisomerizations per rod is capable of suppressing $>90 \%$ of the rod circulating current. This background, however, could not have been bright enough to suppress the circulating current of immature mouse rods, the sensitivity of which is known to be significantly lower than that attained in adult life (Fulton and Rushton, 1978). In preliminary experiments, it was found that a background of 12 photopic $\mathrm{cd} / \mathrm{m}^{2}$ almost completely eliminated rodmediated a-waves in (P15) dark-adapted ERG recordings, leaving a residual a-wave, the kinetic characteristics of which could be ascribed to the suppression of cone circulating current (Lyubarsky et al., 1999). Additional experiments showed that this conemediated a-wave was similar in shape and amplitude to that recorded in the dark-adapted state in both wt and rd mice at P15, $1 \mathrm{sec}$ after the delivery of a bright conditioning flash (producing 50,000 isomerizations per rod per second) [i.e., following a procedure similar to that reported in Lyubarsky and Pugh (1996) and Pugh et al. (1998)]. Therefore, it was assumed that under the present experimental conditions, the steady background used to isolate cone ERGs did not suppress, or only minimally suppressed, wt and rd cone responses.

Figure $8 A$ shows representative cone-mediated ERGs obtained from a wt and an rd mouse at P15, the age at which most reliable responses were recorded from rd mice. It can be seen that, compared with the wt responses, rd ERGs are reduced in amplitude and show profound changes in their waveforms. More specifically, the b-waves are markedly slowed in latency, time-topeak, and duration. As a consequence of the b-wave latency increase, the time-to-peak of the a-wave is also substantially increased, compared with the wt a-wave. In Figure $8 B$ these differences are quantified as means \pm SE recorded from four $w t$ and rd mice. It can be seen that, at all intensities, cone-mediated a-wave amplitudes are reduced, on average, by $50 \%$ compared with wt values. Mean b-wave amplitudes of rd mice show increasing losses as flash intensity increases. The greatest mean loss is observed at the maximum intensity $(10 \times$ decrease $)$ and is by far greater than that observed for the a-wave amplitude.

An attempt was also made to compare the changes in response kinetics with light intensity of both cone-mediated a-waves and b-waves from rd and wt mice at P15. The leading edge of cone a-wave is thought to reflect mostly the suppression of cone circulating current (Hood and Birch, 1995; Smith and Lamb, 1997), although a contribution of off-bipolar cells cannot be excluded (Sieving et al., 1994; Bush and Sieving, 1996), whereas the b-wave is shaped by the contribution of both on- and off-bipolar cells (Sieving et al., 1994). Figure $9 A$ shows a-wave response families recorded at increasing intensities $\left(0.2,2\right.$, and 20 photopic $\mathrm{cd} / \mathrm{m}^{2}$ per second) from an rd and a wt mouse. In Figure $9 B$, the normalized amplitudes, measured at fixed times after stimulus onset, and the normalized initial slopes (see Materials and Meth- 


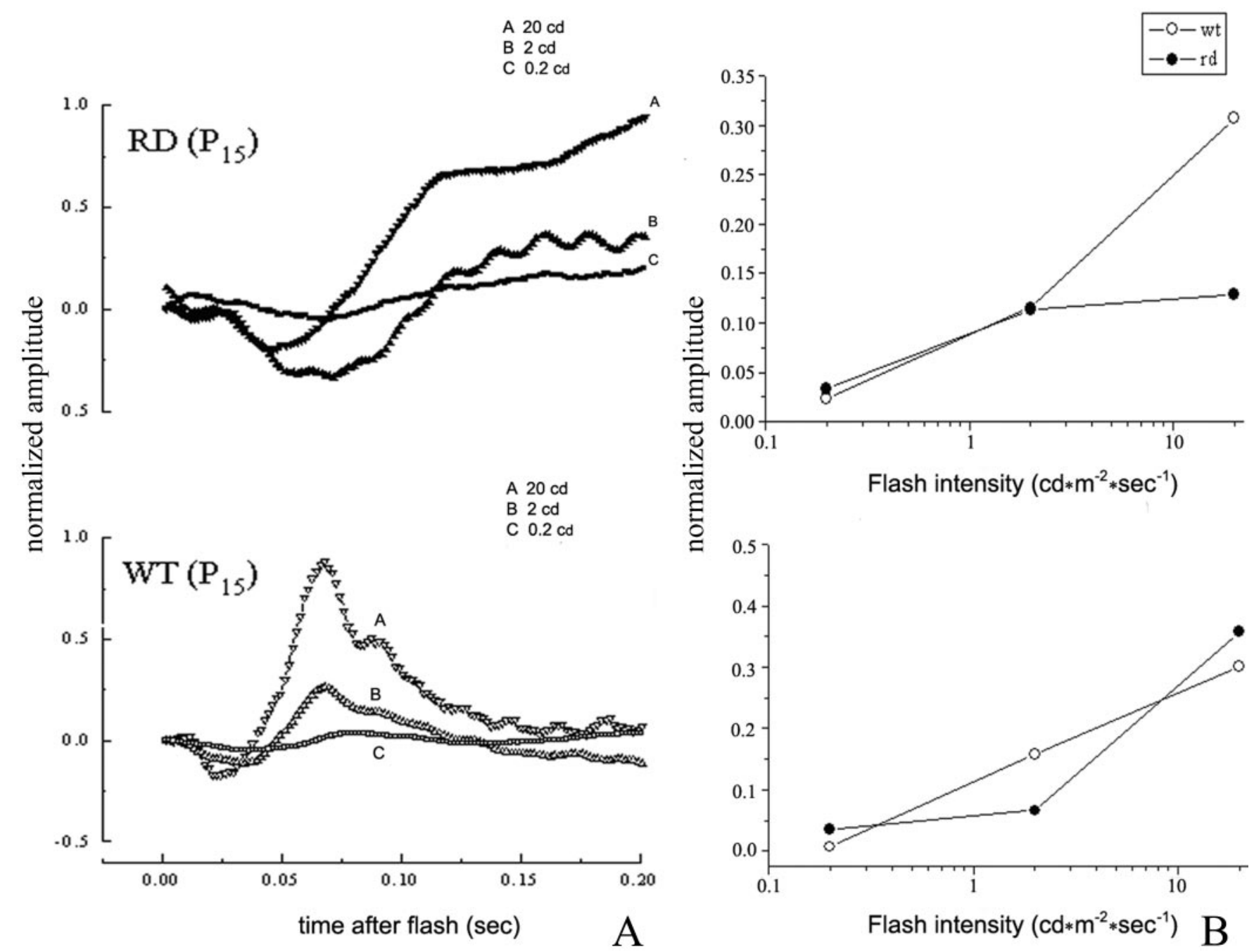

Figure 10. A, Response families of cone-mediated b-waves recorded at increasing flash intensities $\left(0.2,2\right.$, and $20 \mathrm{~cd} / \mathrm{m}^{2}$ per second) from one $\mathrm{rd}$ and one wt animal. $B$, Normalized amplitudes (measured at fixed times after stimulus onset) and initial slopes of the same responses shown in $A$.

ods) of the a-waves shown in Figure $9 A$ are compared for both animals. The rd mouse a-waves show reduced sensitivity (i.e., the light intensity required to reach a given normalized amplitude is $0.8 \log$ units greater in the rd compared with the wt animal) and a reduced normalized initial slope, compared with the wt a-waves. The rd normalized initial slope appears to be more reduced at higher compared with lower flash intensities. Changes in both parameters indicated reduced sensitivity and altered kinetics of the rd cone a-waves compared with wt controls.

In Figure $10 A$ the response families of cone-mediated $b$-waves recorded at increasing flash intensities $\left(0.2,2\right.$, and $20 \mathrm{~cd} / \mathrm{m}^{2}$ per second) from one rd and one wt animal are shown. Normalized amplitudes (measured at fixed times after stimulus onset) and initial slopes of the same responses are compared for both animals in Figure $10 \mathrm{~B}$. The b-wave amplitude of the rd mouse is lower, at the intermediate intensity, and slightly larger, at the lowest and highest intensity, than that of wt mouse (Fig. 10B). This behavior reflects mostly a significant departure from linearity for the rd b-wave amplitude compared with wt amplitude that, in agreement with other studies (Lyubarsky et al., 1999), is linear in the same intensity range. The lower slope at the two lowest intensities of the rd, compared with the wt amplitude, may reflect a loss in light sensitivity. The initial slope of normalized response reveals a change in the b-wave kinetic for the rd mouse compared with the control. This is mainly reflected by the slope difference at the highest intensity.

Flicker ERG responses obtained in the wt and rd mouse at different temporal frequencies between 0.1 and 20 flashes per second are shown in Figure $11 A$. Responses of the rd animal are shown on a normalized scale to allow better comparison of waveforms with those of the control. It is evident that in the rd, unlike in the wt control, ERG responses are dominated by the negative component, and by increasing the flash rate, the sluggish positive response component became progressively more attenuated. This confirms a general trend already observed for the single flash responses, where the rd b-wave not only is attenuated but also undergoes substantial waveform changes, being delayed and with longer duration than that observed in the control (Fig. $11 B$ ). In addition, the flicker experiment provides further evidence that the cone-mediated ERG abnormality in the rd mouse involves more the b-wave than the a-wave component.

Figure $11 C$ shows the mean $( \pm \mathrm{SD})$ amplitudes and times-topeak of the b-wave recorded at different postnatal ages in $\mathrm{rd}$ and wt mice. In wt animals, there are progressive, significant increases in amplitude $\left(F_{(4,18)}=21.64 ; p<0.01\right)$ as well as a decline in time-to-peak $\left(F_{(4,18)}=19.8 ; p<0.01\right)$. Values close to those 


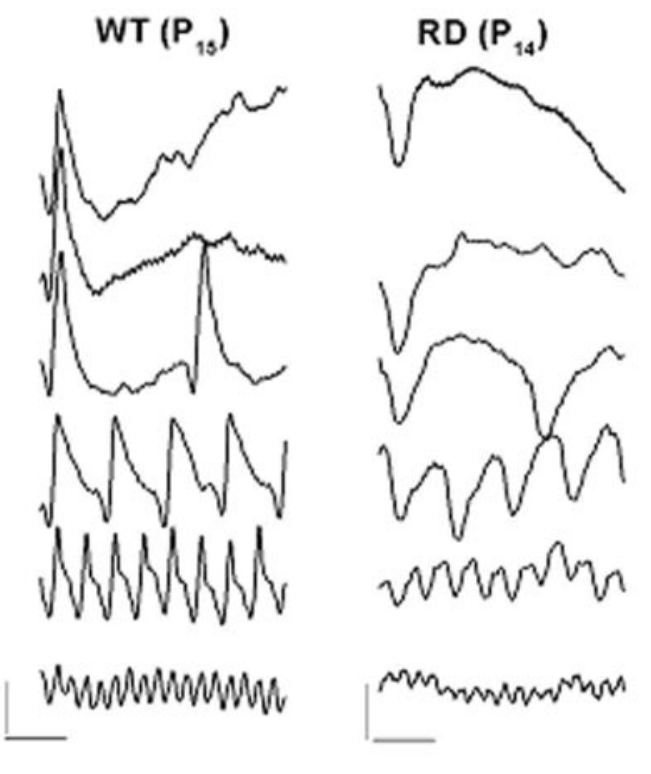

A

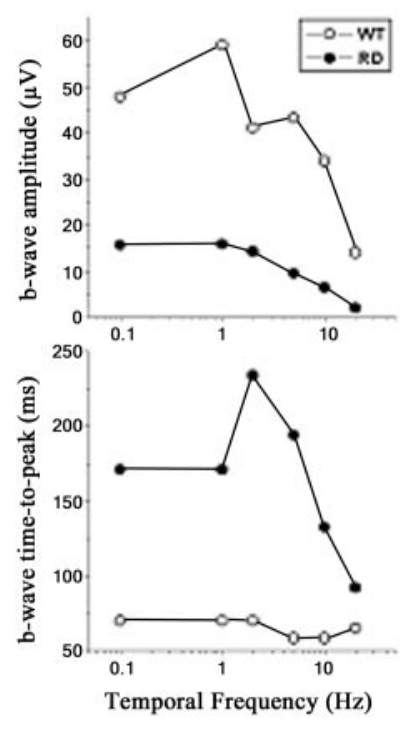

B
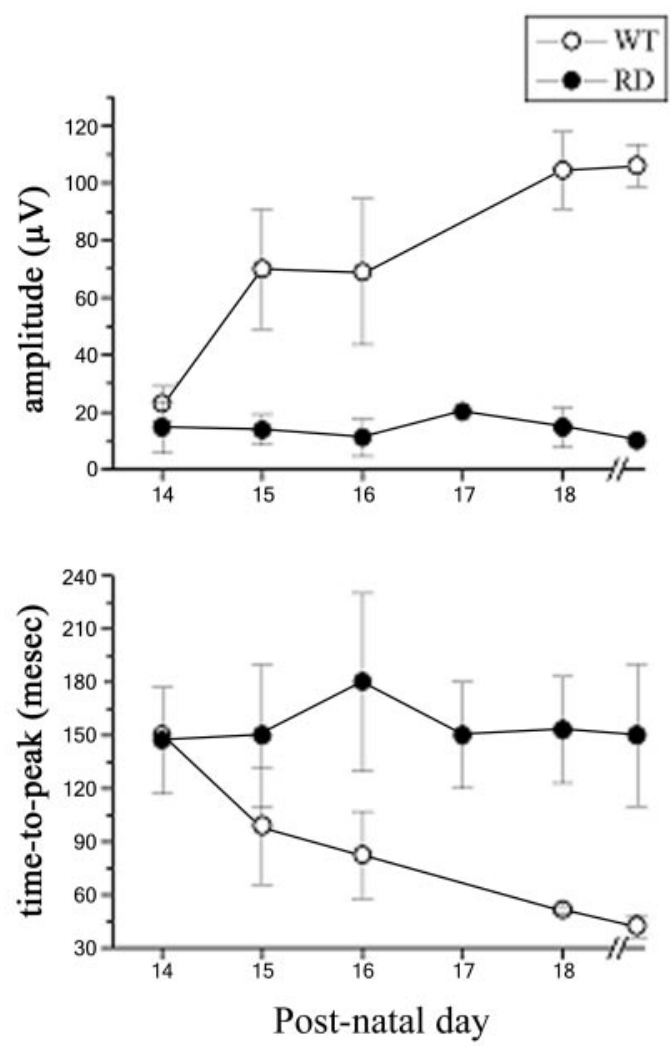

$\mathrm{C}$

Figure 11. A, Cone-mediated flicker ERGs obtained at different temporal frequencies for a wt and an rd mouse at P15 and P14, respectively. Vertical calibration bar indicates 20 and $10 \mu \mathrm{V}$ for the wt and rd mouse, respectively. Horizontal bar indicates 20 msec for both animals. $B$, Peak-to-peak b-wave amplitudes and times-to-peak plotted as a function of temporal frequency for both animals. $C$, Mean $( \pm \mathrm{SD})$ amplitudes and times-to-peak of the cone ERG b-wave recorded from wt and rd mice at different ages. Adult values (P60) are also shown for comparison. $n=4-6$ animals for each group and postnatal day. Note the rapid increase in amplitude and shortening in time-to-peak in wt animals between P14 and P18. By contrast, no changes can be observed in $\mathrm{rd} b$-waves during the same time window.

observed in adult animals are observed at P18. In rd mice, mean amplitudes and times-to-peak do not change significantly with postnatal age, maintaining the values observed at P14. Overall, these data indicate that cone-mediated $b$-waves of rd mice, unlike those of wt, show no signs of maturation throughout the second postnatal week. In rd mice, mean amplitudes and times-to-peak do change significantly with postnatal age, maintaining the values observed at P14.

\section{DISCUSSION}

In this paper we provide conclusive evidence that inner retinal neurons in a well established model of retinitis pigmentosa undergo a series of impressive changes accompanying and following photoreceptor loss. Changes fall into two groups: sprouting of processes in horizontal cells and underdevelopment of dendrites in rod bipolar cells, and later retraction of dendrites in cone bipolar cells. A Müller glial reaction, in the form of GFAP transient hyperexpression, is also described. Thus, we describe early-onset alterations in the morphology of some rod-related neurons (rod bipolars, axonal arborizations of horizontal cells) and upregulation of GFAP in Müller cells during the acute phase of rod photoreceptor death. Later, cone-connected neurons (cone bipolar cells, cell bodies of horizontal cells) also undergo major modifications. It has to be noted that changes in second-order neurons appear first in those cells that establish connections with photoreceptors at the time of their death (such as rod bipolars and axonal complexes of horizontal cells), as though they were more vulnerable to photoreceptor degeneration at the time of synaptogenesis. This is confirmed by the fact that AII amacrine cells, which receive major synaptic input from rod bipolars but establish connections in the IPL well before the onset of photoreceptor degeneration, remain normal, like dopaminergic and cholinergic amacrines.

The morphological changes recall closely the effects of trophic factor deprivation in various neurons, in which one of the first consequences of nurturing molecule removal is retraction of dendrites. The release of diff usible molecules capable of affecting survival from normal retinas has been proven recently (MohandSaid et al., 1998). Most probably, bipolar cells receive trophic information from photoreceptors that guide and sustain the appropriate development of their dendritic arbors. Without such trophic signals, dendrites first underdevelop and then, inevitably, undergo atrophy.

Possibly as a consequence of uncompleted development of the outer part of the cells, rod bipolar axonal endings also stop their growth, to retain immature morphology. Single varicosities in the inner plexiform layer never reach the adult size, whereas their synapses display underdeveloped ultrastructural features. Thus, synaptogenesis is altered not only in the OPL of the rd retina, as described in classic studies (Blanks et al., 1974a,b), but also in the IPL. This suggests a correlation between proper development of 
axonal arborization and normal growth of dendritic arborization. Horizontal cells, instead, change from an actively searching, sprouting status to secondary hypertrophy and loss of thin processes. Their changes appear different in cell bodies (connected to cones) as compared with axonal arborizations (postsynaptic to rods). They first start to sprout and later disorganize spatially before the cell bodies and their dendrites. This suggests that (1) events detected in horizontal cells are related to signals transmitted through the synaptic connections with photoreceptors, and (2) separate districts of the same cell (cell body vs axonal complex) receive different messages and react with different cytoskeletal responses in time. Cone bipolar cells, as compared with rod bipolars, succeed in reaching a mature morphology. This is reasonable, because cone photoreceptors develop normally in the rd and die only later as compared with rods (LaVail et al., 1997); however, cone bipolar cells also eventually lose their normal complement of dendrites in the OPL.

On the contrary, amacrine cells, which develop synaptic connections before bipolar and horizontal cells, do not appear to react to photoreceptor degeneration. It can be concluded that both short-term, synaptogenesis-related changes and, later, modifications of second-order neurons are quite dramatic in the rd mutation. This has to be taken into account when devising strategies to cure RP, because they probably have to be designed very early to prevent the secondary effects on inner retinal cells.

Physiological modifications related to changes in the inner retina of the rd mutant mouse are also quite striking. If a decrease in the amplitude of cone-generated a-waves of the ERG is quite predictable on the basis of a diminished cone response, a much larger decrease of the b-wave can only be explained on the basis of a selective deficit of second-order neurons. Alternatively, alterations in the efficacy of the synaptic transmission between photoreceptors and cone bipolar cells could be responsible. In particular, because the positive b-wave is thought to reflect mostly the activity of depolarizing cone bipolar cells, a decreased sensitivity (or a lower concentration) of metabotropic glutamate receptors on the dendrites of such bipolar cells could explain a delay and a change of shape in the response of depolarizing neurons. Because we have observed decreased immunoreactivity and displacement of mGluR6 in the OPL of developing rd retinas (Strettoi and Pignatelli, 2000), this could explain the changes demonstrated by means of ERG recordings.

Quantitative analysis of the dark-adapted a- and b-waves of the heterozygous rd mouse was performed in the past by Low (1987). It was found that at low stimulus intensities, a-waves were slower compared with those of control animals, and a- and b-wave sensitivities were increased compared with controls. The results were interpreted in terms of reduced rates of cGMP metabolism. In Low's study, however, no quantitative analysis of the ERG of the homozygous $\mathrm{rd} / \mathrm{rd}$ mouse was reported, and isolated conemediated responses were not evaluated. Other studies (Frasson et al., 1999) evaluated the dark-adapted a- and b-waves of the $\mathrm{rd} / \mathrm{rd}$ mouse; however, no quantitative analysis of sensitivity and kinetics of these components in the dark- or light-adapted state were attempted.

All together, we demonstrate clearly that there are profound, early detectable physiological and morphological changes in the inner retina of the rd mutant mouse. These changes take place both during postnatal development (so that they appear time related to synaptic events in the retina) and later in life, suggesting that in different forms of retinitis pigmentosa, usually appearing when synaptogenesis is well completed, atrophy and apoptosis of second-order neurons have to be expected. Thus, even in the fortunate outcome of gene therapy or successful rescue of photoreceptors in retinal degeneration, attention has to be paid to prevent or circumvent secondary effects on key neurons of the inner retina. It is possible that the presence of transplanted cells is capable, by itself, of partially reversing some of the modifications described in second-order neurons, as shown by some authors (Kwan et al., 1999).

\section{REFERENCES}

Acland GM, Aguirre GD, Ray J, Zhang Q, Aleman TS, Cidecyian AV, Pearce-Kelling SE, Anand V, Zeng Y, Maguire AM, Jacobson SG, Hauswirth WW, Bennett J (2001) Gene therapy restores vision in a canine model of childhood blindness. Nat Genet 28:92-95.

Ali RR, Sarra GM, Stephens C, Alwis MD, Bainbridge JW, Munro PM, Fauser S, Reichel MB, Kinnon C, Hunt DM, Bhattacharya SS, Thrasher AJ (2000) Restoration of photoreceptor ultrastructure and function in retinal degeneration slow mice by gene therapy. Nat Genet 25:306-310.

Bennett J, Tanabe T, Sun D, Zeng Y, Kjeldbye H, Gouras P, Maguire AM (1996) Photoreceptor cell rescue in retinal degeneration (rd) mice by in vivo gene therapy. Nat Med 2:649-654.

Bennett J, Zeng Y, Bajwa R, Klatt L, Li Y, Maguire AM (1998) Adenovirus-mediated delivery of rhodopsin-promoted bcl-2 results in a delay in photoreceptor cell death in the $\mathrm{rd} / \mathrm{rd}$ mouse. Gene Ther 5:1156-1164.

Blanks JC, Adinolfi AM, Lolley RN (1974a) Synaptogenesis in the photoreceptor terminal of the mouse retina. J Comp Neurol 156:81-94.

Blanks JC, Adinolfi AM, Lolley RN (1974b) Photoreceptor degeneration and synaptogenesis in retinal-degenerative (rd) mice. J Comp Neurol 156:95-106.

Bowes C, Li T, Danciger M, Baxter LC, Applebury ML, Farber DB (1990) Retinal degeneration in the rd mouse is caused by a defect in the beta subunit of rod cGMP-phosphodiesterase. Nature 347:677-680.

Bush RA, Sieving PA (1996) Inner retinal contributions to the primate photopic fast flicker electroretinogram. J Opt Soc Am A 13:557-565.

Bush RA, Hawks KW, Sieving PA (1995) Preservation of inner retinal responses in the aged Royal College of Surgeons rat. Evidence against glutamate excitotoxicity in photoreceptor degeneration. Invest Ophthalmol Vis Sci 36:2054-2062.

Carter-Dawson LD, LaVail MM, Sidman RL (1978) Differential effect of the rd mutation on rods and cones in the mouse retina. Invest Ophthalmol Vis Sci 17:489-498.

Chaitin MH, Ankrum MT, Wortham HS (1996) Distribution of CD44 in the retina during development and the rds degeneration. Brain Res Dev Brain Res 94:92-98.

Cidecyian AV, Jacobson SG (1993) Negative electroretinograms in retinitis pigmentosa. Invest Ophthalmol Vis Sci 34:3253-3263.

de Raad S, Szczesny PJ, Munz K, Reme CE (1996) Light damage in the rat retina: glial fibrillary acidic protein accumulates in Müller cells in correlation with photoreceptor damage. Ophthalmic Res 28:99-107.

Eisenfeld AJ, LaVail MM, LaVail JH (1984) Assessment of possible transneuronal changes in the retina of rats with inherited retinal dystrophy: cell size, number, synapses, and axonal transport by retinal ganglion cells. J Comp Neurol 223:22-34

Falsini B, Iarossi G, Porciatti V, Merendino E, Fadda A, Cermola S, Buzzonetti L (1994) Postreceptoral contribution to macular dysfunction in retinitis pigmentosa. Invest Ophthalmol Vis Sci 35:4282-4290.

Famiglietti Jr EV (1983) "Starburst" amacrine cells and cholinergic neurons: mirror-symmetric on and off amacrine cells of rabbit retina. Brain Res 261:138-144.

Farber DB, Lolley RN (1974) Cyclic guanosine monophosphate: elevation in degenerating photoreceptor cells of the $\mathrm{C} 3 \mathrm{H}$ mouse retina Science 186:449-451.

Fariss RN, Li ZY, Milam AH (2000) Abnormalities in rod photoreceptors, amacrine cells, and horizontal cells in human retinas with retinitis pigmentosa. Am J Ophthalmol 129:215-223.

Frasson M, Sahel JA, Fabre M, Simonutti M, Dreyfus H, Picaud S (1999) Retinitis pigmentosa: rod photoreceptor rescue by a calcium-channel blocker in the rd mouse. Nat Med 5:1183-1187.

Fulton AB, Rushton WA (1978) The human rod ERG: correlation with psychophysical responses in light and dark adaptation. Vision Res 18:793-800

Galli-Resta L, Novelli E, Volpini M, Strettoi E (2000) The spatial organization of cholinergic mosaics in the adult mouse retina. Eur $\mathbf{J}$ Neurosci 12:3819-3822.

Gan WB, Grutzendler J, Wong WT, Wong RO, Lichtman J (2000) Multicolor "DiOlistic" labeling of the nervous system using lipophilic dye combinations. Neuron 27:219-225.

Gouras P, Du J, Kjeldbye H, Yamamoto S, Zack DJ (1994) Long-term 
photoreceptor transplants in dystrophic and normal mouse retina. Invest Ophthalmol Vis Sci 35:3145-3153.

Gustincich S, Feigenspan A, Wu DK, Koopman LJ, Raviola E (1997) Control of dopamine release in the retina: a transgenic approach to neural networks. Neuron 18:723-736.

Haverkamp S, Wassle H (2000) Immunocytochemical analysis of the mouse retina. J Comp Neurol 424:1-23.

Hood DC, Birch DG (1995) Phototransduction in human cones measured using the alpha-wave of the ERG. Vision Res 35:2801-2810.

Horsburgh GM, Sefton AJ (1987) Cellular degeneration and synaptogenesis in the developing retina of the rat. J Comp Neurol 263:553-566.

Jansen HG, Sanyal S (1992) Synaptic plasticity in the rod terminals after partial photoreceptor cell loss in the heterozygous rds mutant mouse. J Comp Neurol 316:117-125.

Jeon CJ, Strettoi E, Masland RH (1998) The major cell populations of the mouse retina. J Neurosci 18:8936-8946.

Jimenez AJ, Garcia-Fernandez JM, Gonzalez B, Foster RG (1996) The spatio-temporal pattern of photoreceptor degeneration in the aged rd/rd mouse retina. Cell Tissue Res 284:193-202.

Jomary C, Vincen KA, Grist J, Neal MJ, Jones SE (1997) Rescue of photoreceptor function by AAV-mediated gene transfer in a mouse model of inherited retinal degeneration. Gene Ther 4:683-690.

Kwan AS, Wang S, Lund RD (1999) Photoreceptor layer reconstruction in a rodent model of retinal degeneration. Exp Neurol 159:21-33.

LaVail MM, Matthes MT, Yasumura D, Steinberg RH (1997) Variability in rate of cone degeneration in the retinal degeneration $(\mathrm{rd} / \mathrm{rd})$ mouse. Exp Eye Res 65:45-50.

Li ZY, Kljavin IJ, Milam AH (1995) Rod photoreceptor neurite sprouting in retinitis pigmentosa. J Neurosci 15:5429-5438.

Lolley RN, Farber DB (1976) Abnormal guanosine 3',5'-monophosphate during photoreceptor degeneration in the inherited retinal disorder of $\mathrm{C} 3 \mathrm{H} / \mathrm{HeJ}$ mice. Ann Ophthalmol 8:469-473.

Low JC (1987) The corneal ERG of the heterozygous retinal degeneration mouse. Graefes Arch Clin Exp Ophthalmol 225:413-417.

Lund RD, Coffey PJ, Sauve Y, Lawrence JM (1997) Intraretinal transplantation to prevent photoreceptor degeneration. Ophthalmic Res 29:305-319.

Lyubarsky AL, Pugh Jr EN (1996) Recovery phase of the murine rod photoresponse reconstructed from electroretinographic recordings. J Neurosci 16:563-571.

Lyubarsky AL, Falsini B, Pennesi ME, Valentini P, Pugh Jr EN (1999) UV- and midwave-sensitive cone-driven retinal responses of the mouse: a possible phenotype for coexpression of cone photopigments. J Neurosci 19:442-455.

Mohand-Said S, Deudon-Combe A, Hicks D, Simonutti M, Forster V, Fintz AC, Leveillard T, Dreyfus H, Sahel JA (1998) Normal retina releases a diffusible factor stimulating cone survival in the retinal degeneration mouse. Proc Natl Acad Sci USA 9514:8357-8362.

Ogilvie JM, Tenkova T, Lett JM, Speck J, Landgraf M, Silverman MS (1997) Age-related distribution of cones and ON-bipolar cells in the rd mouse retina. Curr Eye Res 16:244-251.

Ogilvie JM, Speck JD, Lett JM (2000) Growth factors in combination, but not individually, rescue rd mouse photoreceptors in organ culture. Exp Neurol 161:676-685.

Peachey NS, Goto Y, al-Ubaidi MR, Naash MI (1993) Properties of the mouse cone-mediated electroretinogram during light adaptation. Neurosci Lett 162:9-11.

Pugh Jr EN, Falsini B, Lyubarsky AL (1998) The origin of the major rod- and cone-driven components of the rodent electroretinogram and the effect of age and light-rearing history on the magnitude of these components. In: Photostasis and related phenomena (Williams TP, Thistle AB, eds), pp 93-128. New York: Plenum.

Rice DS, Curran T (2000) Disabled-1 is expressed in type AII amacrine cells in the mouse retina. J Comp Neurol 424:327-338.

Robson JG, Frishman LJ (1995) Response linearity and kinetics of the cat retina: the bipolar cell component of the dark-adapted electroretinogram. Vis Neurosci 12:837-850.

Robson JG, Frishman LJ (1996) Photoreceptor and bipolar cell contributions to the cat electroretinogram: a kinetic model for the early part of the flash response. J Opt Soc Am A 13:613-622.

Rohrer B, Korenbrot JI, LaVail MM, Reichardt LF, Xu B (1999) Role of neurotrophin receptor TrkB in the maturation of rod photoreceptors and establishment of synaptic transmission to the inner retina. J Neurosci 19:8919-8930.

Santos A, Humayun MS, de Juan EJ, Greenburg RJ, Marsh MJ, Klock IB, Milam AH (1997) Preservation of the inner retina in retinitis pigmentosa. A morphometric analysis. Arch Ophthalmol 115:511-515.

Sanyal S, De Ruiter A, Hawkins RK (1980) Development and degeneration of retina in rds mutant mice: light microscopy. J Comp Neurol 194:193-207.

Sheedlo HJ, Jaynes D, Bolan AL, Turner JE (1995) Mullerian glia in dystrophic rodent retinas: an immunocytochemical analysis. Brain Res Dev Brain Res 85:171-180.

Sieving PA, Murayama K, Naarendorp F (1994) Push-pull model of the primate photopic electroretinogram: a role for hyperpolarizing neurons in shaping the b-wave. Vis Neurosci 11:519-532.

Smith NP, Lamb TD (1997) The a-wave of the human electroretinogram recorded with a minimally invasive technique. Vision Res 37:29432952.

Stone JL, Barlow WE, Humayun MS, de Juan E, Milam AH (1992) Morphometric analysis of macular photoreceptors and ganglion cells in retinas with retinitis pigmentosa. Arch Ophthalmol 110:1634-1639.

Strettoi E, Pignatelli V (2000) Modifications of retinal neurons in a mouse model of retinitis pigmentosa. Proc Natl Acad Sci USA 97:11020-11025

Strettoi E, Raviola E, Dacheux RF (1992) Synaptic connections of the narrow-field, bistratified rod amacrine cell (AII) in the rabbit retina. J Comp Neurol 325:152-168.

Takahashi M, Miyoshi H, Verma IM, Gage FH (1999) Rescue from photoreceptor degeneration in the rd mouse by human immunodeficiency virus vector-mediated gene transfer. J Virol 73:7812-7816.

Vardi N (1998) Alpha subunit of Go localizes in the dendritic tips of ON bipolar cells. J Comp Neurol 395:43-52.

Vardi N, Duvoisin R, Wu G, Sterling P (2000) Localization of mGluR6 to dendrites of $\mathrm{ON}$ bipolar cells in primate retina. J Comp Neurol 423:402-412

Wang X, Tay SS, Ng YK (2000) An immunohistochemical study of neuronal and glial cell reactions in retinae of rats with experimental glaucoma. Exp Brain Res 132:476-484.

Woch G, Aramant RB, Seiler MJ, Sagdullaev BT, McCall MA (2001) Retinal transplants restore visually evoked responses in rats with photoreceptor degeneration. Invest Ophthalmol Vis Sci 42:1669-1676.

Yazulla S, Studholme KM, Pinto LH (1997) Differences in the retina GABA system among control, spastic mutant and retinal degeneration mutant mice. Vision Res 37:3471-3482.

Zeng XX, Ng YK, Ling EA (2000) Neuronal and microglial response in the retina of streptozotocin-induced diabetic rats. Vis Neurosci 17:463471. 